\title{
The Moral Case for the LEGALISATION OF VOLUNTARY EUTHANASIA
}

\author{
Graham Oddie*
}

If a person is suffering from some illness or disability and wishes to end their life the law ought to facilitate rather than frustrate that choice argues Graham Oddie in this article. He points out the inconsistencies in current medical practice, and the gross disparity between the practice and the letter of the law. In dismissing many of the commonly raised objections to calls for reform of the law permitting euthanasia he makes a strong case for consistency in our approach to the right to die and patient autonomy.

\section{INTRODUCTION}

In the light of the rise and fall of the law permitting a form of euthanasia in the Northern Territories, the leaders of the main political parties called for a public debate on the issue of the moral and legal permissibility of euthanasia in New Zealand. Surprisingly, almost everybody -including the clergy, physicians, politicians, ethicists and almost anybody who gives it any sustained thought-already endorses the moral permissibility of euthanasia. However this endorsement is usually highly partial. Certain rather subtle kinds of euthanasia are deemed to be morally permissible, whereas other more obvious kinds are deemed to be cases of murder. The debate is thus not really about whether euthanasia is morally permissible, and hence whether it should be legalised at all, but rather which kinds of euthanasia are morally permissible, and how the practice of euthanasia should be legally regulated.

The distinction which undergirds this partial endorsement of euthanasia is that between killing and letting-die. Intentionally taking active steps to terminate the life of a person is thought to be always and everywhere seriously wrong. By contrast, failing to take steps to prevent a person from dying when it would be possible to do so is thought to be, at least on some occasions, morally permissible. Many think that killing an innocent person is such a

BA Hons (Otago), PhD (London), Professor of Philosophy at the University of Colorado at Boulder. 
serious moral wrong that it should always be illegal-regardless of factors such as degree of suffering, the desire to be killed, or the giving of informed consent to be killed. But many of the same people who take this view nevertheless think that it can also be morally permissible to fail to take "extraordinary measures" to prevent a death, and further that it should not always be illegal to withhold life-saving treatment. Active euthanasia (killing) is always morally wrong, and should be legally forbidden. Passive euthanasia (merely lettingdie) may be morally permissible, even morally praiseworthy, and there should be provision in the law for legitimate application of it.

I will argue that there is a deep incoherence in this asymmetric treatment of euthanasia. The asymmetry is rampant in common-sense morality, but also in medical thinking and medical practice. There are two ways of eliminating the asymmetry, of treating active and passive euthanasia on a par. One would be to deem all forms of euthanasia, both active and passive, equally impermissible, both morally and legally. The other would be to endorse the permissibility of active euthanasia in cases which are in all other respects just like permissible cases of passive euthanasia. The former would lead to unacceptable, indeed bizarre, results.

\section{KILLING AND LETTING DIE: A BARE-DIFFERENCE ARGUMENT}

\section{A What is a bare-difference argument?}

In trying to determine whether the presence or absence of a certain feature is good or bad in itself the method of bare differences is often employed. The idea is really rather simple. If a feature really is a bad one, then wherever it occurs it must make some difference for the worse. Thus, supposing the feature to be bad, if two possible situations differ solely in the presence/absence of that feature then the situation in which it is present should be worse, overall, than the situation in which the feature is absent. The two situations are barely different because they differ only over the feature in question - everything else is held fixed. Now if we can find two such barely different situations which do not differ in overall value, then the feature over which they differ cannot be morally relevant.

Suppose we have a pair of situations, A and B, which differ only in one respect-A has feature $P$ and $B$ lacks it. If $P$ were an intrinsically bad feature then $A$ would have to be worse than B. So if, intuitively, there is absolutely no moral difference between A and B, then $\mathrm{P}$ cannot be bad in itself. Call this the bare-difference principle. Note that, given this principle, if you want to refute the claim that $P$ is an intrinsically morally bad feature, you need to find a pair of possible situations which differ only over the presence of $P$, but which do not differ in value, or differ in any morally interesting way.

A scientific analogy might help here. How does one determine whether a factor (like the presence of oxygen) is causally relevant to some process (like burning)? One devises an experiment in which the only difference is the presence/absence of oxygen. If a candle in a 
jar with oxygen will burn, but an otherwise similar candle in a jar without oxygen will not burn, then we know that the presence of oxygen has something to do with burning: it is causally relevant to burning. However if we shine a blue light on the one candle and a red light on an otherwise exactly similar candle, and both burn, then that seems enough to refute the claim that the colour of light shining on the candle is relevant to burning. This is a bare difference argument in the realm of causal relevance. Bare difference arguments in the realm of moral relevance work in an analogous way.

Consider the example of a bare difference argument. A patient, suffering in the advanced stages of terminal cancer, is given morphine in increasingly high doses to control the pain. What should happen if, accidentally, the morphine suppresses the respiratory system and the patient stops breathing? There will often be an instruction in place, or an informal understanding amongst the patient's care-givers, not to use any "extraordinary measures" to resuscitate him or her. The rationale for this is clear. If the patient were to stop breathing death, even though entirely preventable, would be a blessing. It is thus considered morally permissible to allow the patient to die, for the reason that death would be better for him or her than continuing to live. Letting people die because their lives are an unnecessary burden to them is passive euthanasia. Few argue against passive euthanasia in such cases. Is there anybody who thinks that every technical means available should be employed to stop people dying whenever they could be dragged back from death? We all recognise that would often be both stupid and cruel. However, many who endorse passive euthanasia, hold it to be grossly immoral to administer morphine, to the terminally ill patient in the above case, in doses which would bring about the very same effect, in the very same way, for the very same reason it is welcomed in the case of passive euthanasia-namely, that death would be a blessing. How can the very same outcome, so welcome in the one case be so abhorrent in the other? What makes the difference?

The answer can only be that killing someone, taking deliberate steps to bring about the end of a life, is always and everywhere a terribly bad thing, something which, in itself, is worse, much worse, than merely letting someone die. This is what the debate about the moral permissibility of euthanasia boils down to. It is not whether euthanasia is morally permissible, but whether active euthanasia (killing) is as morally permissible as passive euthanasia (letting-die ).

\section{B Bare difference and the killing/letting-die distinction}

Suppose a person with a severe condition, painful as well as totally disabling, without any prospect of improvement, has repeatedly asked for his or her life-support machine to be turned off - something he or she cannot manage for themself. With the machine on, his or her body will continue to function in its present state indefinitely. So to deliberately turn off the machine in order to end the patient's life would be to kill him or her. 
Now imagine two different scenarios:

Case 1 The physician listens to the patient's arguments, agrees with the their assessment of their condition, feels the patient has very good reasons for preferring death to life that cannot be disputed, and consults with the patient's loved ones who are all in agreement. The physician then turns the machine off and hangs about to make sure no one else comes in and turns it on again, until sure the patient is dead. This seems to be a clear case of killing the patient.

Case 2 the physician feels the very same way but cannot bring him or herself to kill the patient. While she arguing with the patient about this a cleaner comes in and accidentally and unwittingly pulls the plug out, plugs in the vacuum cleaner, and merrily starts vacuuming. At first the physician is horrified. But then it dawns on him or her that if she or he does nothing she or he cannot be justifiably accused of killing the patient. By doing nothing, the doctor will merely have allowed the patient to die. Doing nothing to stop the patient dying will be a case of passive euthanasia, something which the doctor and her colleagues practice every other day - whenever treatment is withheld because it would merely prolong an agonising existence.

In case 1 the physician kills the patient. In case 2 , the physician merely allows him to die. There is definitely a difference between the two cases - killing and letting die are different and yet there appears to be no significant moral difference between them. The physician who allows the patient to die certainly seems no better than the physician who kills him.

It follows from this simple thought experiment that in itself it is not worse to kill than to allow to die. For if it were then in comparing two cases that differ only in that one is a killing and the other an letting-die, we would feel compelled to judge that the killing is morally worse - and we don't. ${ }^{1}$

\section{The role of intentionality}

It is important to see that the distinction between killing and letting-die has little to do with intentionality, or mens rea. It is not the case that the one who kills has ipso facto a different sort of intention from the one who allows to die. Killings may be either intentional or unintentional. In case 1 the doctor intentionally kills the patient, whereas in case 2 the

\footnotetext{
I Rachels was the first to present an argument of this form in the euthanasia debate in his article which originally appeared as the "Active and Passive Euthanasia" (1975) 292 Nerv England Journal of Medicine 78 reprinted in $5 \mathrm{M}$ Fisher and M Ravizza, (eds) Ethics: Problems and Principles (New York, Harcourt, Brace Jovanovich, 1992) 106. In his book The End of Life (Oxford, Oxford University Press, 1986) Rachels elaborates the argument and dubs the technique that of "bare-difference". The technique is actually an ancient one. For a quite different application see G Oddie, "Addiction and the Value of Freedom" (1993) 7(5) Bioethics 373-401.
} 
cleaner unintentionally kills the patient. In case 2 the doctor intentionally lets the patient die. We can also imagine cases of an unintentional letting-die. ${ }^{2}$

Let us concentrate on intentional killing and intentional letting-die which are the salient categories in this context. In intentionally killing, one intends to do something in order to bring about a death which would not otherwise occur. One intends that a death come about through one's intervention into a process. However, in the case of intentional letting die one also intends that a death come about, this time through lack of intervention which would prevent it. In case 1 the doctor intentionally kills the patient. In case 2 the doctor intentionally lets the patient die. To intentionally let something happen you have to be able to prevent it, know you can prevent it, and intentionally fail to prevent it. In both cases, intentionally killing and intentionally letting-die, the intention is that a death come about, either through intervention or lack of intervention. What is crucial to the distinction is the role one plays in the causal ancestry of the death, not in one's intention that a death come about. Euthanasia, whether active or passive, is intentional. Active euthanasia is an intentional act; passive euthanasia is an intentional omission. The intended upshot is the same: that a death, which need not occur at that time, actually occur at that time.

It does not follow from this that intentionally killing someone is not typically a bad thing. Nor does it follow that killing is not typically worse than letting die. A typical killing has lots of horrible features which a typical letting-die lacks - malicious intent, unnecessary suffering, acting without the killee's informed consent, violation of certain special rights, and so forth. But it is these concomitant horrible features which make the typical killing worse than a typical letting-die. And it is precisely in those situations in which the badness of killing humans is controversial - in the case of the terminally or congenitally ill, say - that these other horrible features may well be absent from a killing and present in an letting die. The point of the kind of "bare-difference" argument I have elaborated is to force us to abstract from the typical concomitants of killing or of letting-die and focus on the difference which killing and letting-die themselves sustain. What does this difference contribute to the morality of the situation? And the answer appears to be: none.

\section{$D$ The Doctrine of Double Effect}

A related, but complicating, issue is the notorious doctrine of double effect. This doctrine is also grounded in supposed differences in intentionality. According to the doctrine it is permissible to do something which produces a very bad outcome so long as it is the

2 Suppose there is an automatic fuse-switch on the plug of the life-support machine. When the cleaner turns on the vacuum cleaner the circuit is overloaded and the life-support plug automatically fuses. The cleaner notices this but can't be bothered resetting it because it would involve walking all the way across the room. By failing to reset the plug the cleaner unintentionally allows the patient to die. 
unintended although foreseen side-effect of pursuing a very good end. However it is wrong to use the bad outcome as the intended means to pursuing the good outcome, even if the goodness of the good end outweighs the badness of the bad means.

Consider the case we started with - the terminally ill patient who requires large doses of morphine to control the pain. There can be a fine line between the amount of morphine required to keep the patient comfortable, and the amount that would suppress his or her respiratory system. The doctor is entitled to administer large doses of morphine in order to control the patient's pain, even if that might have the unintended side-effect of stopping the patient's breathing and causing death. However, the doctor is not entitled to administer the very same large doses of morphine in order to increase the probability of suppressing the respiratory system. Palliative care which produces the unintended side-effect that a person dies before they would otherwise have died is permissible. But an intentional use of the very same procedures to shorten a life by the very same amount is not permissible.

The doctrine does have at least one virtue: it provides a moral and legal shelter for what is effectively active euthanasia, and those who find it difficult to face up to the fact that what they are doing is shortening lives can take refuge in that shelter. But the doctrine is a notoriously difficult one to sustain rationally. Consider an extreme case. Suppose any dose capable of killing the patient's pain would also certainly kill the patient. Can anyone with full knowledge of this situation really administer the required dose intending only to kill the pain, but not to kill the patient? And even if it were possible could anything of deep moral significance turn on such refined mental gymnastics? Should the possession of such an ability make the difference between social disgrace and a hefty prison term on the one hand, and respectability and freedom on the other?

\section{E The Soundness of Bare-Difference Arguments}

Some philosophers have tried to undermine bare-difference arguments. ${ }^{3}$ But their arguments do not impugn the limited purpose to which I put this style of argument here. There are really only two possible escape routes for those who reject the conclusion that killing is no worse, in itself, than letting-die.

The first is to deny the intuitive judgement on cases 1 and 2, and to simply to insist that there really is a big difference in value between then, and further that the case of killing is much worse than the case of letting-die. But this would be to allow one's theoretical commitments to override what I have usually found to be quite clear and decisive intuitive judgments people make about these two cases. Such theoretical overriding of clear-cut moral

See S Kagan "The Additive Fallacy" reprinted in Fisher and Ravizza, above n 1, 252-271. For a reply see H Malm "In Defense of the Contrast Strategy" in Fisher and Ravizza, above n 1, 272-277. 
intuitions would, if practised generally, make any criticism of high-level moral theories well-nigh impossible.

The second is to deny the bare-difference principle that if $\mathrm{P}$ is, say, intrinsically bad then a situation A featuring P must be worse than any barely different situation lacking P. Thus one could retain the judgement that killing is worse, in itself, than letting-die, but deny that this implies that case 2 should thereby be judged worse than case 1 . The problem with this is that denial of the bare-difference principles appears to empty the concept of intrinsic badness. If a feature's being intrinsically bad does not contribute or add to overall disvalue then what interesting consequences flow from the attribution of intrinsic badness? What use would the notion of intrinsic badness be. In particular, if killing is worse than lettingdie, but the bare-difference principle is false, then we cannot conclude that a situation's involving a killing makes it any worse than a comparable situation involving a letting-die. Thus if a letting-die is sometimes permissible, then nothing in the badness of killing would prevent some comparable killings being permissible as well. The denial of the baredifference principle would thus render the thesis of the intrinsic badness of killing totally ineffective in any argument against active euthanasia.

Given that killing is not worse, in itself, than letting-die, three other possibilities present themselves. One is that letting-die is worse, in itself than killing. However, it would not be hard to construct a bare-difference argument against that thesis. Indeed, if you think that case 1 , in which the physician lets her patient die, is no worse than case 2 , in which she kills him, then we already have such an argument up and running. A second possibility is that the two are simply not comparable for value. They are evaluatively incommensurable. The third is that they are comparable and evaluatively equivalent. Thus if killing and letting-die can be compared for intrinsic value then they are, in themselves, evaluatively equivalent. In what follows I will assume that the two are evaluatively commensurable, and hence in themselves, evaluatively equivalent.

\section{EUTHANASIA UNDER NEW ZEALAND LAW}

Some legal codes replicate, to a greater or lesser extent, the supposed asymmetry between killing and letting-die, or more generally between doings and allowings, embedded in our everyday moral discourse. The Crimes Act 1961 is, however, remarkably neutral between doings and allowings (or between acts and omissions). Indeed, it goes somewhat further than this even handedness by effectively denying the very distinction between killing and letting-die. ${ }^{4}$ In s 158 homicide is defined as "[T\}he killing of a human being by another,

\footnotetext{
Note that it is no part of my argument that there is no difference between killing and letting-die, or between doing and allowing. Rather, it is that in itself this perfectly good distinction between killing and letting-die carries no moral relevance. Criticisms of the bare-difference argument often conflate these two quite different points.
} 
directly or indirectly, by any means whatsoever". Killing a human may be either culpable or not, as specified in $\$ 160$ :

(1) Homicide may be either culpable or not culpable.

(2) Homicide is culpable when it consists in the killing of any person:

(a) By an unlawful act; or

(b) By an omission without lawful excuse to perform or observe any legal duty; or

(c) By both combined; or

(d) By causing that person by threats or fear of violence, or by deception, to do an act which causes his death; or

(e) By wilfully frightening a child under the age of 16 years or a sick person.

(3) Except as provided in section 178 of this Act, culpable homicide is either murder or manslaughter.

(4) Homicide that is not culpable is not an offence.

Already here we have a hint that the Act does not recognise the distinction between killing and allowing to die. Subsection (2)(b) entails that some omissions (or allowings) if they lead to death, are cases of killings. However, this is conditional upon the omission being the failure to perform a legal duty. Section 151 adds specific details of when such legal duties obtain:

(1) Every one who has charge of any other person unable, by reason of detention, age, sickness, insanity, or any other cause, to withdraw himself from such charge, and unable to provide himself with the necessaries of life, is (whether such charge is undertaken by him under any contract or is imposed upon him by law or by reason of his unlawful act or otherwise howsoever) under a legal duty to supply that person with the necessaries of life, and is criminally responsible for omitting without lawful excuse to perform such duty if the death of that person is caused, or if his life is endangered or his health permanently injured, by such omission.

(2) Everyone is liable to imprisonment for a term not exceeding 7 years who, without lawful excuse, neglects the duty specified in this section so that the life of the person under his charge is endangered or his health permanently injured by such neglect.

These three sections taken together render a whole swag of everyday cases of passive euthanasia not only illegal, but cases of culpable homicide, indeed of murder. Suppose an elderly patient who is incapacitated and bedridden by a severe stroke develops pneumonia. The pneumonia could be treated quite simply by a cheap course of antibiotics. (Note that 
such a treatment hardly counts as an "heroic and extraordinary" attempt to prolong life!) But often the practitioner will discretely inquire of the relatives whether they want the treatment pursued or withheld. To withhold it, however, would make the physician and the relatives liable to prosecution under s 151. Take s 151 together with ss 158 and 160, and they are liable to a charge of culpable homicide. If it can be shown that their intention, in with holding the antibiotics, was to significantly raise the probability of the death of the elderly patient, then under $s 167^{5}$ they are presumably liable to a charge of murder rather than of manslaughter.

Section 157 widens the scope of the applicability of this even handed treatment beyond those with professional legal duties:

Every one who undertakes to do any act the omission to do which is or may be dangerous to life is under a legal duty to do that act, and is criminally responsible for the consequences of omitting without lawful excuse to discharge that duty.

Finally, in ss 164 and 165 this even handed treatment of acts and omissions is extended beyond those who have specific legal duties to the populace as a whole.

Every one who by any act or omission causes the death of another person kills that person, although the effect of the bodily injury caused to that person was merely to hasten his death while labouring under some disorder or disease arising from some other cause.

Everyone who by any act or omission causes the death of another person kills that person, although death from that cause might have been prevented by resorting to proper means.

Thus any omission which accelerates a death counts as a case killing. Whether or not the killing is culpable depends, of course, on the fulfilment of $s$ 160. It follows that in legal terms killing is much more widespread both in the medical profession and outside of it than we formerly thought. Every time you fail to give as much as you could to famine relief you are not letting people die, you are killing them.

5 Section 167 Provides:

Culpable homicide is murder in each of the following cases:

(a) If the offender means to cause the death of the person killed:

(b) If the offender means to cause to the person killed any bodily injury that is

known to the offender to be likely to cause death, and is reckless whether death ensues or not:

(c) If the offender means to cause death, or, being so reckless as aforesaid, means to cause such bodily injury as aforesaid to one person, and by accident or mistake kills another person, though he does not mean to hurt the person killed:

(d) If the offender for any unlawful object does an act that he knows to be likely to cause death, and thereby kills any person, though he may have desired that his object should be effected without hurting any one. 
The Crimes Act here has distorted the normal concept of killing out of all recognition. This is confused as a piece of conceptual analysis of the concepts involved. Nevertheless underlying the confusion is the genuine insight that the distinction between killing and letting-die should carry the kind of normative freight in the law which, according to commonsense, it is supposed to carry in morality. In other words, those who drew up the Act clearly thought that the Law should not treat acts and omissions totally differently. But there are two ways of ensuring parity of legal treatment. One is to regard every case of intentionally letting-die as comparable to an otherwise similar case of intentional killing, about which the Law takes a very dim view. The other is to revise the law on intentional killings to make it accord with our intuitive moral judgments about comparable cases of intentional allowings to die. ${ }^{6}$

\section{TRADITIONAL ARGUMENTS AGAINST ACTIVE EUTHANASIA REVISITED}

In the light of the moral equivalence of active and passive euthanasia it will be instructive to review some of the leading arguments put forward against the moral and legal permissibility of active euthanasia. In each case, the kind of argumentation which is typically employed against active euthanasia produces either absurd or demonstrably false consequences when applied to passive euthanasia.

$6 \quad$ It is interesting to note that when the Federal Government in Australia passed the Euthanasia Laws Act 1997, it amended the Northern Territory (Self-Government) Act 1978 to include s 50A which reads:

(1) Subject to this section the power of the Legislative Assembly conferred by section 6 in relation to the making of laws does not extend to the making of laws which permit or have the effect of permitting (whether subject to conditions or not) the form of intentional killing of another called euthanasia (which includes mercy killing) or the assisting a person to terminate his or her life.

(2) The Legislative Assembly does have power to make laws with respect to:

(a) the withdrawal or withholding of medical or surgical measures for prolonging the life of a patient but not so as to permit the intentional killing of the patient; and

(b) medical treatment in the provision of palliative care to a dying patient, but not so as to permit the intentional killing of the patient; and

(c) the appointment of an agent by a patient who is authorised to make decisions about the withdrawal or withholding of treatment; and

(d) the repealing of legal sanctions against attempted suicide.

This passage is clearly at odds with New Zealand law in its account of what killing amounts to, and tends to reinforce the asymmetry between active and passive euthanasia. (I am indebted to Duncan Webb for drawing these provisions to my attention.) 
If I am right about this, the Crimes Act has achieved parity in exactly the wrong way, and is thus badly in need of radical reform. This analysis is supported by those cases in which the courts have considered the ability of medical staff to bring on death by omission, and the judgment has been more in accord with the common-sense approval of passive euthanasia. For example, Auckland Area Health Board $v$ Attorney General ${ }^{7}$ seemed to conclude that non intervention was justified where treatment could not "prevent cure or alleviate a disease which threatened life or health". It is also of note that where a doctor has assisted the death of a patient the courts have shown lenience in sentencing occasionally not imprisoning the offender: $R v R u s c o e{ }^{8}$ In $R \quad v$ Cox a doctor who (unsuccessfully) injected a terminally ill patient to cause death was given a 12 month suspended sentence. This suggests that the courts are already realigning judgments on active euthanasia with judgments on comparable cases of passive euthanasia. ${ }^{10}$

\section{A The sanctity of life}

Opponents of euthanasia often appeal to the "sanctity of life" principle and claim that euthanasia would violate it. The idea is that human beings are special, even unique, in that their simply being alive is of enormous value. Perhaps being alive is of infinite value, or at least overriding value compared with the kinds of goods and evils that fill a life. This would explain why proponents of the sanctity of life principle often dismiss the evil of suffering as inconsequential or trivial compared with the value of life as such. Given a suitable version of the principle, it follows that it cannot be right to take a life, even your own, just to bring avoidable suffering to an end.

Suppose the principle of the sanctity of life were strong enough to make it wrong to kill someone to relieve their suffering. Suppose that killing and letting-die are evaluatively commensurable. Then since killing is evaluatively equivalent to letting-die, it would be equally wrong to let someone die in order to relieve suffering, when their death could be prevented. If the sanctity of life principle entails that the value of being alive always outweighs the disvalue of any possible suffering, then given equivalence it cannot be permissible to allow preventable deaths to avoid suffering. The fact that we do think it morally permissible to allow people to die when their lives are full of pointless suffering shows that we really do not hold the sanctity principle at all. Rather, we think that the value of being alive can sometimes be outweighed by the disvalue of the suffering that fills such a life.

$7 \quad$ [1993] 1 NZLR 235.

8 (1992) 8 CRNZ 68.

$9 \quad$ (1992) 12 BMLR 1.

10 Again, I am indebted to Duncan Webb for drawing these cases to my attention. 


\section{B Playing God}

A different sort of argument appeals to the idea that God alone is entitled to decide when a person should live and when she should die. We shouldn't "play God". The idea is, of course, totally unacceptable as a basis for law-making in a largely secular state. Many, maybe most, people in New Zealand don't even believe God exists, let alone claim intimate knowledge of what God thinks about matters such as these. But that is not the objection I wish to raise against it. Suppose it really does entail that we should never carry out active euthanasia. Then, by evaluative equivalence, it also entails that we should always allow people to die when intervention would prevent their deaths. If someone will die without intervention, then to prevent his death is to pre-empt God. (That would be very bad news for the medical profession, which is in the daily business of making life and death decisions.)

\section{Professional ethos}

A more promising principle claims that the role of the medical profession is to save life, not to destroy it. Those who work in the medical profession are properly imbued by their training and their practice with a strong pro-attitude to promoting life wherever possible. To ask doctors and nurses and other medical professionals to start actively disposing of lives through active euthanasia would be to ask them to adopt incompatible attitudes to the sick and dying.

If this is right, then it is not clear how we can justify the expectation that the medical profession should practice passive euthanasia. Given equivalence, it is just as bad to allow someone to die who might be saved as it is to kill someone who might otherwise live. It seems that by asking the medics to be prepared to allow salvageable lives to perish is already to foist incompatible attitudes on them.

Once we have undermined the moral significance of the doing/allowing distinction, the practice of passive euthanasia is testimony to a quite different underlying medical ethos. The medical profession does not exist primarily to prolong lives. It exists, as do many other professions, to make our lives better than they would otherwise be. Prolonging a life is typically a good means to the end of making that life as good as it can be.

Suffering and illness are always bad in themselves. That is to say, other things being equal, it seems that less suffering and illness is always better than more. So if other things are equal, then it is always justifiable to attempt to remove illness and suffering. So those who have equipped themselves to control suffering and illness should try to eliminate them where they can. Of course, things are not always equal. We live in a world in which the cure can sometimes be worse than the disease. Sometimes the attempt to eliminate a particular illness might produce even more suffering and harm. In such cases a wise medic will not pursue the treatment. This does nothing to impugn that medic's commitment to the underlying ethos of his profession. 
Is death, like suffering and illness, bad in itself? This is harder to evaluate by the method of bare-difference. The problem is that two situations which differ in that in one the person dies and in the other he continues to live probably differ in a myriad of other ways. Exactly how they differ depends crucially on how we conceive of death. Is death the total annihilation of a person, or is it the doorway into a new life in some other realm? If death is the latter, and we hold all other things fixed (degree of suffering, for example) then of course there will not be much to choose between the two. But this argument also shows that we are not really interested here in whether death is bad in itself and here I will not try to determine that. What is clear is that given various assumptions about the nature of death (that it is not, for example, the doorway to an eternity of suffering in hell), there will be actual cases in which we all judge death to be, all things considered, a "blessing". That is, death can be an instrumental good in certain circumstances, regardless of its intrinsic value or disvalue. There can be cases in which death would improve the overall value of a person's life, taken as a whole, and continued life would diminish its value. That we have this view is borne out by the widespread practice of passive euthanasia. Sometimes the attempt to prolong a life can make that life, as a whole, less worth living. And in refraining from prolonging a life, a medic bears witness to the fact that preserving life is not her overriding goal at all. Rather, the real goal is that of enabling the doctor's patients to lead lives which, by their own lights, are as good as they can be given the less than perfect world which we dwell in.

Once we recognise that the underlying purpose of the medical profession is not preserving life at all costs, but making lives as good as they can be in an imperfect world, the standard professional ethos argument against active euthanasia also collapses. ${ }^{11}$

\section{The possibility of hope}

Opponents of euthanasia often point out that, whereas death is final, while a person is still alive there is "always room for hope", and it is too risky to presume that their lives are not going to improve radically.

The claim that there is always room for hope is usually exaggerated. But more importantly, even when it might just be possible that life will improve, it might not be worth the costs of pursuing such an improvement. (It is just possible that this week you will buy the winning Lotto ticket, but that does not make it rational to exchange your house for Lotto tickets.) Now consider passive euthanasia again. For some terminal conditions there are treatments which would slightly improve one's chances of survival. Suppose such a

11 In any case, nothing in the original argument would prevent us from setting up a quite different profession of "euthanasists", whose professional duties would include making sure people were not forced to live longer than they themselves judged valuable. (I owe this point to Fred Robinson, an active campaigner for euthanasia.) 
treatment were very painful and, if unsuccessful, would remove whatever enjoyment you might have left. It is neither immoral nor stupid to refuse such treatment. I doubt whether any sane person would argue for legislation forcing people to undergo such treatments. With passive euthanasia we allow people to forego a small chance of survival in order to avoid the near certainty of future pain and suffering. The mere possibility of a miraculous recovery is thus not in itself a good reason to cling to life. By equivalence, it is also not a good reason to reject active euthanasia if such is the only means available to ending what would otherwise be a painful and pointlessly slow demise.

\section{E The Slippery Slope}

Opponents of legalising active euthanasia sometimes concede that it might be occasionally justified, but argue that legalisation is the top of a slippery slope, at the bottom of which is a Brave New World. Voluntary active euthanasia blends, by borderline cases, into involuntary active euthanasia of those whose lives others deem not worth living - the old, the disabled, the weak and defenceless. This argument usually goes with another - that of guilt by association. (We all know what happened in Nazi Germany!) The very word "euthanasia" conjures up images of concentration camps and torturous lethal experiments on helpless, non-consenting minorities. Consider the following argument from George and Porth: ${ }^{12}$

What sort of society would creation of a right to assisted suicide help us to become. ....[I]t would be likely to lead to moral deterioration and a slide from acceptance of suicide as a 'rational' and legitimate choice to acceptance of 'mercy killing' with or without the victim's consent and even to the disposal of those who desire to cling to life but whose desire is deemed selfish or irrational. ...[T] he slope becomes very slippery very fast as soon as a society begins acting on the proposition that some people are better off dead. ... [O]nly sentimentality stands in the way of embracing the concept of "lebensunswertes Leben" - "life unworthy of life".

This kind of slippery-slope argument is perhaps the hardest to evaluate. It has to be admitted that it is possible that even if active euthanasia is no worse than passive euthanasia, nevertheless the legalisation and open practice of active euthanasia might have bad effects on our attitudes to the dying and the elderly, attitudes which are not induced by the current practice of passive euthanasia. The legalisation of active euthanasia might make us lose our grip on the value of life, to see sick, elderly or disabled people as nuisances which we would be well rid of. Family members might bring pressure to bear on their elderly or sick, because of the debilitating financial and emotional costs of caring for them. Physicians might end up regarding the taking of life as a small matter, something which

12 R George and W Porth "Death, be not Proud" National Reviezv June 26, 1995, 49-52, 52. 
doesn't necessarily require the informed consent of the patient, for example. It might be much easier to take peoples lives without obtaining the consent of any of the relevant parties.

I want to make two points about this kind of argument. Firstly, we should not lose sight of the simple point that there is an important distinction between voluntary and involuntary euthanasia, and that this distinction cuts across the active-passive distinction. The voluntary-involuntary distinction is all too obviously a morally significant one, and one that in recent years has been slowly but surely gaining ground across the medical domain. It is the main distinction which needs to be clarified and regulated in any proposed legislation concerning end-of-life decisions. Currently it is not at all clear that when euthanasia, passive or active, is carried out it is carried out with desire or the informed consent of those killed or allowed to die. Where the distinction is not clear, and clearly enforced, there is indeed a very dangerous slippery slope from voluntary passive euthanasia to involuntary passive euthanasia. And where active euthanasia is illegal that in itself suppresses open discussion of the issue. Hence active euthanasia is much more likely to be involuntary than voluntary wherever it is illegal and punishable. Any change in the law concerning euthanasia should thus strengthen the general requirement of informed consent not only for treatments but also for withholdings and withdrawings of treatments.

We could certainly make the conditions for ascertaining voluntariness and informed consent so stringent that if we err at all we will err by depriving people who really want to die of their desired end. (This may well be the effect of the constraints in the now repealed Northern Territories legislation.) But compare this again with passive euthanasia. Nobody argues in the following way:

Its being legally permissible to refuse a life-saving treatment puts pressure on people generally to refuse life-saving treatments, even people who really want the treatment. If the life-saving treatment is costly then people who might be saved by it may feel pressure to refuse it from those who foot the bill. This is eroding our sense of the value of life, and we will surely end up with massive under treatment of people whose lives could be saved. Because of this dangerous slippery slope down which we are currently sliding, whenever some treatment might prolong a life, it must be carried out regardless of the well being or expressed wishes of the patient.

Nobody argues like this not only because the conclusion is accepted as morally repugnant, but because it also flies in the face of the facts. People have a moral right to refuse treatments. They are also not obliged to spend large sums of money on costly treatment even if the likely alternative is death. But we do not see the erosion of respect for life which this argument suggests is inevitable. Rather, what we see is a growth in awareness amongst reflective people of the necessity to regulate the striving to prolong life at any cost. Not only is it wasteful of resources which could be spent on improving quality rather than mere quantity of life, but it is actually promoting much unnecessary, pointless suffering. 
This brings me to the second point about these kinds of slippery slope argument. The reason they are sometimes found hard to evaluate has not always been recognised by philosophers. Philosophers like their arguments to be totally a priori, like the baredifference argument which I developed at the start. We do not have to investigate the world in order to lay out such arguments. All we need is a comfortable armchair and a little time to perform some inexpensive thought experiments. The problem with many slippery slope arguments is that they are not amenable to such a priori reasoning. This particular slippery slope argument is like that. It concerns the probable impact of legalisation of euthanasia on attitudes and practices. It thus involves contingent matters of fact about ourselves which can only be decided by a messy empirical investigation. Philosophers are not particularly good at those.

In order to decide whether legalisation would have the kinds of effects predicted we really need to do a rather large-scale social experiment. Take two otherwise fairly similar societies, $\mathrm{A}$ and $\mathrm{N}$, but make them differ in one important respect. In A let there be explicit laws against active euthanasia, while in $\mathrm{N}$ make it possible for doctors to practice euthanasia (both active and passive) openly without fear of legal sanction provided certain guidelines, including provisions for informed consent, are respected. Compare attitudes and practices concerning end-of-life decisions in $\mathrm{N}$ over a period of time. Further, compare attitudes and practices in $\mathrm{N}$ at the end of the experimental period with those in $\mathrm{A}$ at the end of the period. The two comparisons should give us fairly reliable information about the effect of legalisation of euthanasia on attitudes and practices concerned with end-of-life decision. If it turns out that attitudes to end-of-life decisions deteriorate in $\mathrm{N}$, and that at the end of the period they compare unfavourably with those in A, then we can reasonably attribute the differences to the legislation itself.

The problem with this research proposal is, of course, that it would be morally questionable to carry out a large-scale experiment of this sort when what is at issue is the very moral permissibility of the proposed change in the law! Fortunately, however, we don't have to carry out the experiment in order to gather the requisite data. Two such societies already exist - $\mathrm{A}$ is Australia and $\mathrm{N}$ is the Netherlands. Two surveys were carried out in the Netherlands, one in 1990 and one in 1995, which monitored the change over time of attitudes and practices concerned with end-of-life decisions. The same survey was carried out in Australia in 1995-6. ${ }^{13}$ The following is a brief summary of some of the relevant results:

1. In the Netherlands, between 1990 and 1995 there was a small increase in cases of active voluntary euthanasia-from $1.7 \%$ of all deaths to $2.4 \%$ ( $\pm 0.3 \%)$. In Australia in

13 H Kuhse, P Singer, P Baume, M Clark, and M Rickard, "End-of-Life Decisions in Australian Medical Practice Medical Journal of Australia (17 February, 1997) 166, 191-196. 
1996 the percentage of deaths by active voluntary euthanasia was similar to that in the Netherlands in $1990(1.8 \%)$.

2. In the Netherlands the percentage of active terminations of life without the patient's explicit request or consent fell slightly from $0.8 \%$ to $0.7 \%$. In Australia in 1995/6 the percentage of such deaths was $3.5 \%$ - five times higher than in the Netherlands!

3. In the Netherlands in $199513.5 \%$ of all deaths were preceded by a decision to withhold or withdraw treatment with the intention of hastening death or not prolonging life. In Australia the figure for 1995/6 was 30.5\% Furthermore, in Australia in $22.5 \%$ of cases the treatment was withheld or withdrawn without the patient's explicit consent.

The implications are clear enough. In Australia the practice of bringing lives to an end without explicit request or informed consent is significantly more widespread than it is in the Netherlands, where rates are not only lower but also stable over time. ${ }^{14}$

\section{$V$ AN ARGUMENT FOR LEGALISING EUTHANASIA: THE SLIPPERY SLOPE TILTS BACKWARDS}

Showing that the standard arguments against the legalisation of active euthanasia fail is not tantamount to a positive argument for legalisation. However, the results of the Australian study are not only a severe blow to one of the most popular standard slippery slope arguments against the legalisation of euthanasia. They actually support a powerful argument for the legalisation of euthanasia.

If the rates for involuntary terminations were the same in both countries then that would be sufficient in itself to undermine the soundness of the slippery slope argument. But the higher rates in Australia cry out for an explanation. As the authors of the Australian study point out, one plausible explanation of the higher rates is the very illegality of euthanasia. The practice is illegal and can invite severe sanctions under the law. Nevertheless many practitioners, given their experience of dealing with the dying and chronically ill, have come to the conclusion that the law is quite wrong in this respect. Their belief is strong enough to motivate them to flout the law, provided of course that they can do so without risking severe penalties. So naturally the decisions which they take this will typically be rather secretive. They will not want to discuss these decisions openly with patients or relatives, for fear that their standard practices will be exposed to legal scrutiny. So this will generate a lack of openness. It follows that doctors will have to take decisions into their own hands without

14 A similar study is planned in the United States, to be carried out by the Center for Values and Social Policy, Philosophy Department, University of Colorado at Boulder. 
any consultation with the relevant parties. The upshot is that a considerable number of people are having their lives terminated sooner than they would have liked.

The standard slippery slope argument is revealed by the facts to be bereft of value. But more than this, it seems the facts are best explained by a sharp slope in the opposite direction. It is the illegality of euthanasia which erodes healthy attitudes to the sick and dying and leads to widespread abuse of the chronically and terminally ill. It is the illegality which has generated an elite who control when we live and die without any consultation with those most affected.

\section{CONCLUSION}

In the case of each of the traditional arguments against active euthanasia, an extension of the argument to passive euthanasia yields morally unacceptable or else demonstrably false conclusions. In each case there must be something wrong with the original argument against active euthanasia. Almost everybody who thinks about it seriously and sensitively comes to the conclusion that passive euthanasia can be morally justified - when the burden of life is very considerable, when the dying person rationally prefers to die, when the dying person consents to the process, the death is dignified and painless, and so on. Further, even if this is strictly illegal under the Crimes Act, the courts are now making judgments which gel with commonsense on passive euthanasia. The debate is thus not over the moral permissibility of euthanasia as such, but over whether the same considerations that clearly apply to passive euthanasia should also apply to active euthanasia. The only principled way to block such an extension is to maintain that killing, in itself, is much worse than letting-die. But, as we have seen, that claim is simply unsustainable. Finally, the current law is not only forcing many people to live lives that they do not want to live, it is almost certainly costing the lives of those who do want to go on living. It is time for reform. ${ }^{15}$

15 I owe a big debt to Duncan Webb, for numerous insightful comments and criticisms the first draft of this paper. Unfortunately, I still have to assume responsibility for all the defects of the final version. 